\title{
MENSURAÇÃO DO PERFIL DO POTENCIAL EMPREENDEDOR E SEU IMPACTO NO DESEMPENHO DAS PEQUENAS EMPRESAS
}

Cid Gonçalves Filho ${ }^{1}$

Mara Regina Veit 2

Carlos Alberto Gonçalves ${ }^{3}$

\begin{abstract}
Resumo: 0 empreendedorismo tem sido um tema amplamente difundido no ambiente acadêmico. Vários livros, artigos e conferências têm inspirado pesquisadores a buscar identificar o perfil do potencial empreendedor. Embora haja esses esforços e 0 crescente interesse sobre 0 assunto, existe uma lacuna no que se refere à existência de instrumentos válidos, capazes de mensurar esse perfil quantitativamente, em suas diversas dimensões. Nesse sentido, foi elaborado este estudo, que contou com 965 questionários respondidos por empresários de pequenas empresas brasileiras. A escala PPE (Perfil do Potencial Empreendedor) foi considerada válida pelos testes aplicados. No modelo estrutural, verifica-se que o perfil empreendedor foi responsável por explicar 25\% do desempenho das empresas, impacto esse considerado relevante, o que sugere a importância da mensuração e do desenvolvimento do perfil empreendedor.
\end{abstract}

Palavras-chave: Empreededorismo. Pequena Empresa. Desempenho.

\section{INTRODUÇÃO}

Em uma sociedade empreendedora, que vem constantemente estimulando 0 espírito dessa natureza, os indivíduos considerados empreendedores enfrentam enormes desafios, que precisam explorar como oportunidades, transformando o aprendizado nesse campo na arte de gerar resultados concretos, com muita disciplina e persistência. São esses indivíduos que impulsionam a economia, provendo novos bens de consumo e inovadores métodos de produção (DRUCKER, 2003; SCHUMPETER, 1982; TIMMONS, 1989).

Uma parcela significativa de estudos científicos sobre o tema busca analisar o comportamento empreendedor, procurando identificar comportamentos, ações e atitudes que 0 diferenciam do ser humano "normal". Esses estudos também expõem características pessoais de sucesso que norteiam aqueles que desejam trabalhar por conta própria. É cada vez mais crescente o número de estudos e pesquisas realizadas na tentativa de entender as forças psicológicas e sociológicas que movem 0 empreendedor de sucesso. Cada pesquisador, usando uma lógica e uma metodologia estabelecida em seus próprios campos de estudo, tem direcionado esforços significativos na identificação das características empreendedoras. Podem-se destacar os autores que iniciaram as primeiras pesquisas sobre o comportamento empreendedor, como McClelland (1961), que desenvolveu uma pesquisa aplicada e identificou uma dezena de características de comportamento empreendedor, comuns às pessoas triunfadoras; Schumpeter (1982), que destaca a figura do empreendedor associado ao risco, à

\footnotetext{
1 FUMEC, Nova Lima, MG. E-mail: cid@ face.fumec.br

2 SEBRAE, Belo Horizonte, MG. E-mail: mara.veit@ sebraemg.com.br

3 FUMEC, Belo Horizonte , MG. E-mail: carlos@ face.fumec.br
} 
inovação e ao lucro e Mintzberg (2001), o qual propõe a relação entre 0 empreendedorismo e 0 processo da estratégia do negócio.

Se houver oportunidades de conhecer a mente do empreendedor, como ele pensa, age, executa e transforma a sua história abstrata em fato real, por meio de estudos aplicados, será possível criar atributos que permitam identificar semelhanças e diferenças entre os empreendedores pesquisados. Em complementação, será possível estabelecer índices que, quando analisados e comparados, contribuirão para a criação de parâmetros de análise, e interpretar o potencial empreendedor (TIMMONS, 1989).

0 conjunto de abordagens de diferentes autores sobre o tema empreendedorismo não tem conseguido formar uma compreensão integradora a respeito do significado plausível de quem, de fato, é o empreendedor. É difícil distinguir suas características peculiares, a percepção das oportunidades e dos riscos inerentes a essas características, as escolhas estratégicas e a maneira como 0 empreendedor faz a alocação de recursos na formação do empreendimento. A falta de conformidade também tem impedido o progresso dos pesquisadores, no sentido de construir uma teoria mais sólida na área e de explicar o impacto que a postura empreendedora exerce sobre 0 desempenho organizacional (FILION, 1990; DOLABELA, 2004).

Considerando esse cenário, esta pesquisa foi elaborada com o objetivo de identificar e mensurar o perfil do potencial empreendedor, bem como de verificar o seu impacto no desempenho dos pequenos empreendimentos.

\section{REVISÃO DE LITERATURA}

\subsection{PEQUENAS EMPRESAS}

As pequenas empresas são consideradas como um dos principais agentes de desenvolvimento e crescimento econômico de um país, pois possibilitam duas grandes contribuições para esse resultado: a geração de empregos mais estáveis e duradouros e a criação de inovações tecnológicas. Segundo Timmons (2004), desde a II Guerra Mundial, 50\% das inovações tecnológicas e 95\% das inovações radicais, com foco no rompimento do processo tradicional já instituído, foram originadas em pequenas empresas, demonstrando que, nesses pequenos empreendimentos, a flexibilidade, a criatividade e a oportunidade são elementos essenciais para inovação (TIMMONS, 2004).

No Brasil, segundo os dados das pesquisas realizadas pelo SEBRAE - Serviço Brasileiro de Apoio às Micro e Pequenas Empresas (2004), as pequenas empresas representam $98 \%$ do número total de empresas existentes no país e $59 \%$ da ocupação da mão-de-obra. Assim, essas pequenas empresas são responsáveis por $48 \%$ da produção nacional e $21 \%$ do produto interno bruto, 0 que reforça a tese de que a pequena empresa é responsável, diretamente, pelas taxas de emprego e produção nacional, contribuindo, de forma significativa, com o crescimento e com o desenvolvimento econômico do país. Outros dados demonstram que a taxa de mortalidade dos pequenos negócios, nos dois primeiros anos de existência, atinge 45\% (SEBRAE, 2004).

Muito do sucesso creditado às micro e pequenas empresas, em estágio de maturidade, é creditado ao empreendedor que planeja corretamente o seu negócio e realiza uma análise de viabilidade criteriosa do empreendimento antes de colocá-lo em prática (DORNELAS, 2001). 


\subsection{O POTENCIAL EMPREENDEDOR}

São inúmeros estudos que buscam identificar o perfil empreendedor. Procura-se neste trabalho, então, fazer um resumo sobre o tema, com o apoio de autores clássicos e de pesquisas empíricas realizadas no meio acadêmico e no empresarial.

Em 1961, McClelland iniciou seus estudos sobre o tema empreendedorismo, que foram ampliados em 1982, por meio de um survey com empreendedores de 32 países e corroborados por muitas pesquisas e experimentos posteriores. Foi utilizado um teste de avaliação motivacional - o T.A.T - Thematic Aperception Test - e testes de resolução de problemas cujos resultados demonstraram que 0 indivíduo empreendedor possui uma estrutura motivacional diferenciada, pela presença marcante de uma necessidade específica: a de realização. Para o pesquisador, a motivação pela realização, conjugada com as dez características do comportamento empreeendedor - CCE's, são os fatores essenciais para 0 crescimento econômico dos indivíduos e contribuem para explicar a aparente indiferença de muitos e a sensibilidade de poucos para oportunidades econômicas que se apresentam no ambiente (McCLELLAND, 1961).

O economista Schumpeter (1982) foi um dos primeiros pensadores, que, no início do século $X X$, procurou traduzir o sentido de empreendedorismo, quando descreveu a contribuição dos empreendedores como o processo de destruição criativa na formação de riqueza. $\mathrm{O}$ autor afirma que a essência do empreendedorismo está na percepção e na exploração de novas oportunidades, no âmbito dos negócios, utilizando recursos de maneira inovadora. Para o autor, sem inovação não há empreendedores, sem investimentos, não há retorno de capital e o capitalismo não se propulsiona. $\mathrm{A}$ partir dessa análise, os economistas passaram a ver os empreendedores como detectores de oportunidades de negócios, criadores de empresas e corredores de risco.

Carland, Carland e Hoy (1992) desenvolveram um instrumento para medir o potencial empreendedor de um indivíduo, através do CEI - Carland Entrepreneurship Index, que vem sendo aprimorado e aplicado em outros grupos de pesquisa. Os autores concluíram que o empreendedorismo é uma integração de cinco elementos: necessidade de realização, criatividade, propensão à inovação, ao risco e à postura estratégica, relacionada pelos autores como a busca de oportunidade. Segundo Carland, Carland e Hoy (1992), a maior ou menor presença dessas características em um indivíduo define o seu potencial, segundo a escala $\mathrm{CEI}$, que pontua os respondentes com valores de zero a 33 pontos, contidos em três faixasl: micro-empreendedor, empreendedor e macro-empreendedor. O CEI é um questionário de auto-resposta com trinta e três frases combinadas e afirmativas em pares, no formato de escolha forçada, e seu objetivo principal é identificar o potencial empreendedor dos respondentes. Carland e Carland (1996) e sua equipe de pesquisadores identificaram, nos resultados das pesquisas, três características maiores da personalidade empreendedora, como: a propensão a assumir riscos, a preferência pela inovação e pela criatividade e a necessidade de realização. Esses três fatores integrados, identificados na pesquisa CEI - Carland Entrepreneurship Index, compõem 0 perfil do empreendedor por ele percebido e sua compreensão tem fundamentado a construção de pesquisas sobre o potencial empreendedor (CARLAND, 1996).

A pesquisa GEM - Global Entrepreneurship Monitor, aplicada em 35 países, desde 0 ano de 2000, procura identificar a TEA - Taxa de Empreendedorismo, nos países participantes, considerando os motivos que levam os empreendedores a realizarem empreendimentos, seja por necessidade ou oportunidade. São aplicados 54 critérios na pesquisa, a qual busca também avaliar as condições de competitividade entre os países e os fatores que contribuem para a atividade empreendedora e para as políticas públicas, que estimulam a atividade empresarial. 0 Brasil, que participa da pesquisa, tem ocupado as seguintes posições em relação aos demais países: $2006-5^{\circ}, 2005-7^{\circ}, 2004-7^{\circ} ; 2003$ $-6^{\circ}, 2002--7^{\circ} ; 2004-8^{\circ}$ (GEM/SEBRAE, 2001a, 2006). 


\section{MODELO HIPOTÉTICO}

Observando-se a proposta de Carland e Carland (1996) sobre o potencial empreendedor, bem como estudos de outros autores pesquisados, como de McClelland (1961), de Schumpeter (1982), de Timmons (1989), de Filion (1999), de Mintzberg (2001), de Dornelas (2001),de Drucker (2003) e de Bygrave (2004), o seguinte modelo hipotético é proposto na figura 1.

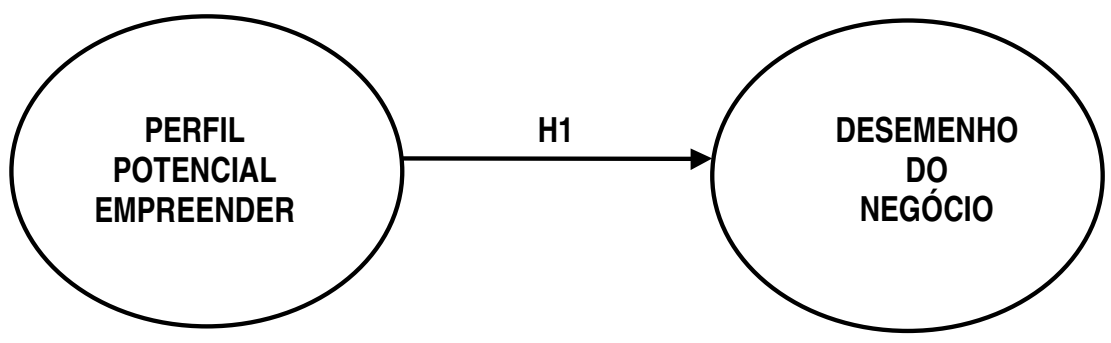

\section{Figura 1: Modelo Hipotético de Pesquisa}

Fonte: os autores

Descreve-se, a partir da figura 1, então, a hipótese nula e a alternativa do modelo:

H0,1: Não existe uma relação linear positiva entre o potencial empreendedor e 0 desempenho de pequenas empresas (o caminho entre os dois construtos é igual a zero).

H1,1: Existe uma relação linear positiva entre o potencial empreendedor e 0 desempenho de pequenas empresas.

\section{MÉTODO}

\subsection{METODOLOGIA}

A pesquisa foi organizada em duas fases distintas. A fase exploratória fez uso de uma abordagem qualitativa, realizando a revisão de literatura e aplicando entrevistas com empreendedores, com especialistas e com estudiosos do tema. A segunda fase teve como foco o desenvolvimento da pesquisa por meio de um survey (abordagem quantitativa).

\subsection{AMOSTRA E COLETA DE DADOS}

A população pesquisada compreende a participação de 965 empresários de pequenas empresas juridicamente constituídas no Estado de Minas Gerais, Brasil, procurando abranger todas as principais regiões do estado. A coleta de dados ocorreu com a utilização de três modalidades distintas: a) correio; b) pontos de atendimento SEBRAE e c) internet. 


\subsection{INSTRUMENTO DE PESQUISA}

O instrumento de pesquisa foi elaborado seguindo uma série de etapas. Inicialmente, foi realizada uma revisão de literatura de autores reconhecidos, como McClelland (1961), Schumpeter (1982), Timmons (1989), Carland e Carland (1996), Filion (1999), Mintzberg (2001), Dornelas (2001), Drucker (2003), e pesquisas realizadas com empresários e empreendedores pelo Sebrae e GEM (2001 a 2006). Em seguida, uma lista de construtos e itens foi submetida a um conjunto de especialistas em empreendedorismo, que contribuíram para aprimorar o instrumento da pesquisa. Após a análise de conteúdo, foi realizado um pré-teste com 35 respondentes, empresários das empresas.

\section{RESULTADOS}

\subsection{ANÁLISE DE DADOS}

\subsubsection{Descrição da amostra}

No que se refere à amostra, observa-se que $67 \%$ dos empreendedores pesquisados são homens e $33 \%$ mulheres, sendo que $70 \%$ dos respondentes possuem idade variando de 21 a 40 anos. Cerca de $57 \%$ são casados e $57 \%$ possuem filhos. Verifica-se que $37 \%$ investiram até US\$ 2.000 no negócio e 14\% aplicaram valores acima de US\$25.000. A origem dos recursos investidos teve duas procedências de maior enfoque: $30 \%$ foram recursos próprios e pessoais e $13 \%$ foram provenientes da família. A maior parte dos empresários criou empresas societárias $(37 \%)$, com foco no setor de serviços $(51 \%)$ e no setor de comércio (19\%). Observa-se que $75 \%$ das empresas têm até cinco funcionários e 53\% abriram seus negócios por observarem uma oportunidade e 37\% apenas por necessidade.

\subsubsection{Análise exploratória dos dados}

A princípio buscou-se uma análise preliminar e verificação de pressupostos de análise, que incluem análise dos dados ausentes, outliers, linearidade e normalidade.

\subsection{AVALIAÇÃO DA FIDEDIGNIDADE DO INSTRUMENTO DE PESQUISA}

\subsubsection{Análise da dimensionalidade das medidas}

Para Netemeyer et al. (2003), a primeira etapa de avaliação da fidedignidade de um instrumento é a verificação da dimensionalidade das medidas: deve-se encontrar quais observou e se as condições para aplicação da análise fatorial eram adequadas, por meio de um resultado significativo no teste de esfericidade de Bartlett e uma medida KMO superior a 0,70 (TABACHNICK e FIDEL, 2001).

Partindo da premissa de que os fatores subjacentes representam aspectos diferenciados do comportamento empreendedor, aplicou-se a rotação oblíqua na interpretação dos dados (direct oblimin), no intuito de simplificar a estrutura fatorial e possibilitar a interpretação dos dados (HAIR et al., 1998). Por fim, lembrando que muitos itens inseridos na análise tratavam de indicadores invertidos da 
escala de diferencial semântico adotada por Carland e Carland (1996), buscou-se minimizar a redundância por meio da exclusão daqueles que, claramente, não acrescentavam a validade de face e conteúdo das medidas, por se tratarem de indicadores antônimos que carregavam os mesmos fatores. Após a exclusão dos itens menos relevantes e dos que não apresentavam cargas significativas (superiores a 0,25 ) foi possível encontrar uma solução fatorial de oito dimensões, apresentada na tabela 1.

Tabela 1 - Análise fatorial exploratória: perfil do potencial empreendedor

\begin{tabular}{|c|c|c|c|c|c|c|c|c|}
\hline \multirow{2}{*}{ INDICADORES } & \multicolumn{8}{|c|}{ FATOR } \\
\hline & 1 & 2 & 3 & 4 & 5 & 6 & 7 & 8 \\
\hline $\begin{array}{l}\text { 37) Eu penso que procedimentos operacionais padrões são } \\
\text { cruciais (I). }\end{array}$ & & 0,73 & & & & & & \\
\hline v01) Ter os objetivos deste negócio por escrito é crucial (N). & & $-0,47$ & & & & & & \\
\hline $\begin{array}{l}\text { v67) Ser sistemático nas definição de procedimentos é crucial } \\
\text { para aprimorar o negócio. }\end{array}$ & & $-0,44$ & & & & & & \\
\hline /15) Um plano deve ser escrito para ser efetivo (N). & & $-0,28$ & & & & & & \\
\hline 130) Eu penso que sou uma pessoa imaginativa (N). & & & 0,79 & & & & & \\
\hline 144) Eu prefiro pessoas que são imaginativas (N). & & & 0,49 & & & & & \\
\hline v04) Eu gosto de pensar que sou uma pessoa criativa (N). & & & 0,41 & & & & & \\
\hline $\begin{array}{l}\text { J38) Eu aprecio o desafio de inventar, mais do que qualquer } \\
\text { coisa }(\mathrm{N}) \text {. }\end{array}$ & & & 0,29 & & & & & 0,26 \\
\hline $\begin{array}{l}\text { J48) Minha vida real é fora deste negócio, com minha família e } \\
\text { amigos (I). }\end{array}$ & & & & 0,53 & & & & \\
\hline $\begin{array}{l}\text { J21) Minhas prioridades incluem muitas coisas fora deste } \\
\text { negócio (I). }\end{array}$ & & & & 0,45 & & & & \\
\hline v47) Meus objetivos pessoais giram em torno deste negócio (N). & & & & 0,41 & & & & \\
\hline $\begin{array}{l}\text { J22) Uma das coisas mais importantes na minha vida é este } \\
\text { negócio }(\mathrm{N}) \text {. }\end{array}$ & & & & 0,40 & & & & \\
\hline $\begin{array}{l}\text { v52) Se você quer exceder a concorrência, você tem que } \\
\text { assumir alguns riscos }(\mathrm{N}) \text {. }\end{array}$ & & & & & 0,81 & & & \\
\hline $\begin{array}{l}\text { v60) Se eu quero que este negócio cresça, preciso assumir } \\
\text { alguns riscos }(\mathrm{N}) \text {. }\end{array}$ & & & & & 0,68 & & & \\
\hline V26) As pessoas que trabalham para mim gostam de mim (I) & & & & & & 0,71 & & \\
\hline $\begin{array}{l}\text { J58) As pessoas pensam em mim como alguém fácil de se } \\
\text { relacionar (I). }\end{array}$ & & & & & & 0,53 & & \\
\hline $\begin{array}{l}\text { v64) Eu me preocupo com os sentimentos das pessoas que } \\
\text { trabalham para mim (I). }\end{array}$ & & & & & & 0,44 & & \\
\hline J23) Eu sou uma pessoa que gosta de pensar e planejar (N). & & & & & & & 0,59 & \\
\hline $\begin{array}{l}\text { J12) Eu gosto de abordar as situações de uma perspectiva } \\
\text { analítica (N) }\end{array}$ & & & & & & & 0,54 & \\
\hline $\begin{array}{l}\text { v09) A coisa mais importante que eu faço para este negócio é } \\
\text { planejar (N). }\end{array}$ & & & & & & & 0,43 & \\
\hline $\begin{array}{l}\text { V34) Eu procuro estabelecer procedimentos padrões para que } \\
\text { as coisas sejam feitas certas (I). }\end{array}$ & & 0,29 & & & & & $-0,38$ & \\
\hline J36) Eu penso que é importante ser lógico (N). & & & & & & & 0,35 & \\
\hline $\begin{array}{l}\text { J14) Eu não descansarei até que sejamos os melhores (N). } \\
\text { J49) Eu adoro a idéia de tentar ser mais esperto que os } \\
\text { concorrentes (N). }\end{array}$ & & & & & & & & $\begin{array}{l}0,42 \\
0,39\end{array}$ \\
\hline $\begin{array}{l}\text { J31) O desafio de ter sucesso é tão importante quanto ganhar } \\
\text { dinheiro }(\mathrm{N}) \text {. }\end{array}$ & & & & & & & & 0,25 \\
\hline
\end{tabular}

Fonte: Dados da pesquisa -2006.

OBS: Medida $\mathrm{KMO}=0,895$; teste de esfericidade de Bartllet significativo $(p<0,001)$. Na tabela são apresentadas somente as cargas com valores superiores a 0,25 . Os fatores explicam $51 \%$ da variância total dos dados. 
Nota-se que um total de oito fatores foi extraído na AFE deste estudo, contrastando os resultados obtidos por Carland e Carland (1996) e Inácio Jr. (2002). Alguns fatores extraídos se coadunam com os originais obtidos pelos autores, tal como o fator risco (segundo fator extraído na AFE), inovação (terceiro fator extraído na AFE). Porém, os fatores personalidade e postura estratégica têm diferenças cruciais quanto aos itens que compõem tais construtos e foram divididos em mais dimensões.

\section{Tabela 2 - Fatores que compõem o PPE - perfil do potencial empreendedor}

\begin{tabular}{c|c}
\hline ORDEM & FATORES DO PPE \\
\hline 01 & Risco \\
\hline 02 & Competência estratégica \\
\hline 03 & Pensamento analítico \\
\hline 04 & Relacionamento \\
\hline 05 & Planejamento formal \\
\hline 06 & Desafio \\
\hline 07 & Inovação \\
\hline 08 & Dedicação \\
\hline
\end{tabular}

Fonte: Dados da pesquisa - 2006.

$\mathrm{Na}$ tabela 2, o primeiro fator aponta a postura pró-ativa e a autoconfiança na estratégia dos empreendedores, sendo denominados de competência estratégica. Cabe lembrar que o fator aqui demonstrado é, notavelmente, diferente da postura estratégica obtida por Carland e Carland (1996), porque é composto por indicadores extraídos de outras fontes da literatura, que não o CEl. O segundo fator demonstra o grau de formalização de procedimento e planos por parte do empreendedor, nomeado como planejamento formal. $O$ terceiro fator é o de inovação, o qual é similar ao obtido originalmente por Carland e Carland (1996) e Inácio Jr. (2002). O quarto fator extraído corresponde ao grau de representatividade do negócio, indicando um aspecto central na vida do empreendedor, em detrimento da sua família e de outras atividades extras do trabalho, sendo, portanto, explicitado como dedicação. $O$ quinto fator representa as facetas de disposição e de aceitação do risco dos negócios, considerado o fator risco e encontrado pelos autores em seu estudo original. $\mathrm{O}$ sexto fator corresponde ao grau em que o empreendedor tem facilidade de relacionamento com seus funcionários e com outros membros do seu círculo profissional, nomeando-o como relacionamento. $O$ sétimo fator aponta para a afinidade do empreendedor com o processo de planejamento formal e com o pensamento analítico do negócio, sendo denominado de pensamento analítico. Por fim, o oitavo fator aponta para o grau em que o empreendedor vê um desafio no sucesso negócio, tal como uma meta de realização pessoal, apresentado como desafio.

Comprova-se que os fatores encontrados para essa escala diferem, significativamente, daqueles obtidos no estudo original de validação do CEI. Importa recordar que Carland e Carland (1996) encontraram poucas evidências da validade de sua estrutura original de quatro fatores para os itens que compõem o $\mathrm{CEl}$. Os próprios autores recomendam que estudos posteriores avaliem a adequação da estrutura fatorial adotada, a despeito da elevada validade primitiva das escalas obtidas. Assim, nesse estudo dos autores mencionados, acredita-se terem sido obtidas evidências de uma dimensionalidade mais robusta do ponto de vista estatístico e conceitual das escalas propostas. Etapas subseqüentes de validação são empreendidas, para verificar as demais propriedades psicométricas das escalas. A partir desse ponto, passa-se a explorar a dimensionalidade da escala de desempenho do negócio, definidos na tabela 3. 


\section{Tabela 3 - Análise fatorial exploratória: desempenho no negócio}

\begin{tabular}{l|c}
\hline \multicolumn{1}{c|}{ INDICADORES } & FATOR1 \\
\hline A empresa tem apresentado crescimento na participação de mercado. & $\mathbf{0 , 8 6}$ \\
A empresa tem alcançado uma posição competitiva frente à concorrência. & $\mathbf{0 , 8 3}$ \\
A empresa tem alcançado crescimento dos lucros no último período. & $\mathbf{0 , 8 2}$ \\
A empresa tem obtido retorno sobre o capital ou recursos investidos no negócio. & $\mathbf{0 , 7 6}$ \\
A empresa tem demonstrado capacidade de manter os clientes leais e fiéis. & $\mathbf{0 , 6 7}$ \\
A empresa tem capacidade para atrair novos clientes no mercado. & $\mathbf{0 , 6 3}$ \\
A empresa tem investido em inovação e tecnologia no desenvolvimento de produtos e serviços. & $\mathbf{0 , 6 0}$ \\
A empresa possui informações/pesquisas sobre produtos e serviços similares no mercado. & $\mathbf{0 , 5 3}$ \\
\hline
\end{tabular}

Fonte: Dados da pesquisa-2006.

OBS: Medida $\mathrm{KMO}=0,872$; teste de esfericidade de Bartllet significativo $(\mathrm{p}<0,001)$. Na tabela são apresentadas somente as cargas com valores superiores a 0,25 . Os fatores explicam $57 \%$ da variância total dos dados.

Observa-se, na Tabela 3, que uma solução unidimensional foi obtida para escala de desempenho, demonstrando que essa escala pode ser considerada como uma faceta única do desempenho da empresa. De fato, isso demonstra que os empreendedores consideram todos os itens nela definidos como facetas do desempenho do negócio. Para verificar o possível impacto de observações influentes sobre os resultados da AFE, tratou-se de fazer uma análise considerando a exclusão dos casos considerados extremos. Nessa análise, observou-se que os fatores formados, tanto para a escala do Perfil do Potencial Empreendedor, quanto para a escala de desempenho organizacional, permaneceram estáveis na solução sem outliers, exceção feita ao fator inovação, que teve uma carga cruzada de alguns indicadores com o fator planejamento formal. Considera-se essa mudança trivial e, de modo a não prejudicar a generalização dos resultados, preferiu-se analisar os resultados considerando aqueles extremos. Em suma, pode-se, nesse tópico, apresentar evidências acerca da dimensionalidade das escalas empregadas.

\subsubsection{Análise da confiabilidade das medidas}

Todos os Alpha tiveram valores acima de 0,6, aceitáveis para estudos exploratórios (NETEMEYER et al., 2003), exceto dois fatores - dedicação e desafio - , com valores de 0,5. Tal ocorrência sugere a realização de mais estudos, para aprimorar a mensuração desses dois fatores, com possível inclusão de novos itens. Aplicou-se a lógica de avaliação da adequação das medidas também para o construto desempenho, obtendo um Alpha de Cronbach de 0,8891.

\subsubsection{Análise da validade convergente}

Quanto à escala de perfil empreendedor, percebe-se que todos os indicadores das respectivas escalas apresentam validade convergente, segundo os critérios de significância das cargas fatoriais, propostos por Bagozzi et al, (1991). Ainda, com apoio dos mesmos critérios, pode-se afirmar que os construtos relacionados ao Perfil Empreendedor têm validade convergente, pois suas cargas apresentam valores significativos com as dimensões dessa escala. Atesta-se, dessa forma, a validade convergente de tais variáveis, conforme critérios sugeridos. $O$ diagrama, a seguir, demonstra o modelo fatorial testado, levando em conta somente a estrutura latente do mesmo, isto é, os indicadores estão omitidos para simplificar a representação gráfica na figura 2. 


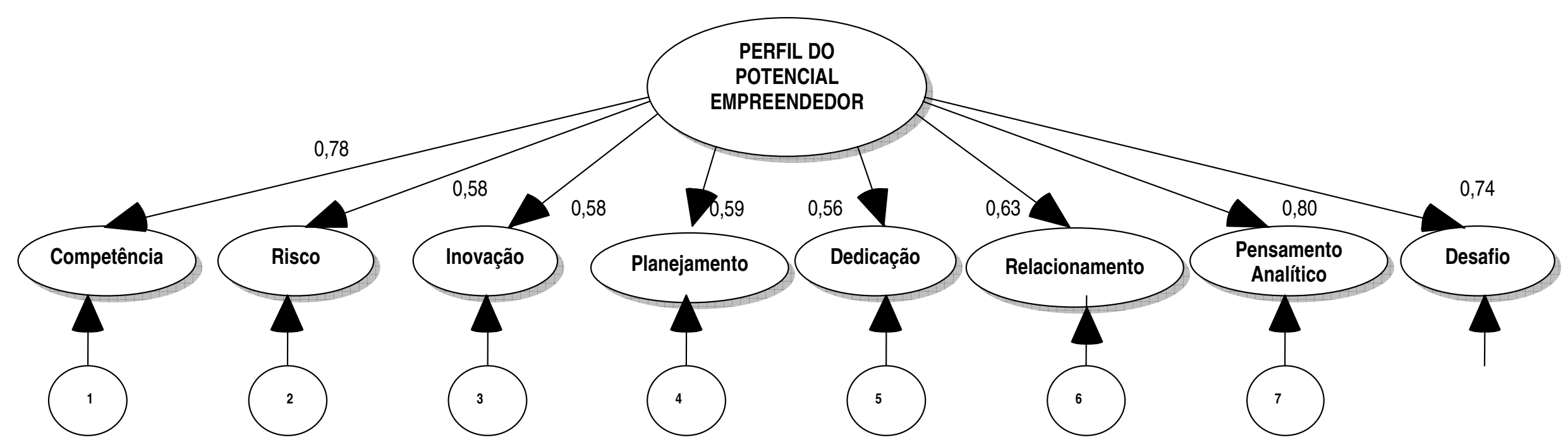

Figura 2 - Resultados da AFC da escala do PPE - Perfil do Potencial Empreendedor

Fonte: Dados da pesquisa - 2006. OBS: todas as cargas padronizadas são significativas ao nível de 0,01\%. 
Observando os índices de ajuste, demonstrado na figura anterior, observa-se que o modelo apresenta um ajuste moderado, conforme sugestões de Hair et al. (1998). A medida GFI (Goodness of Fit Index) pode ser interpretada como uma medida percentual das correlações da matriz de entrada, que são explicadas pelo modelo proposto (TABACHNICK, FIDEL, 2003). Nesse estudo, o valor ficou em 0,89 , indicando que o modelo consegue explicar, aproximadamente, $89 \%$ das correlações originais. Isso aponta que, ao menos, para essas dimensões do construto do Perfil do Potencial Empreendedor, a estrutura fatorial encontra apoio razoável dentro dos limites propostos (KLINE, 1998).

\subsection{CONSIDERAÇÕES SOBRE A MENSURAÇÃO DO PPE - PERFIL DO POTENCIAL EMPREENDEDOR}

De modo a analisar inicialmente os resultados, apresenta-se a tabela 4, com médias dos fatores do PPE (Perfil do Potencial Empreendedor).

Tabela 4 - Médias dos construtos do PPE

\begin{tabular}{l|c|c|c|c|c}
\hline \multicolumn{1}{c|}{ CONSTRUTOS } & N & Mínimo & Maximo & Média & Desvio \\
\hline Competência estratégica & 965 & 4,38 & 10,00 & 8,76 & 1,01 \\
Risco & 965 & 5,00 & 10,00 & 8,93 & 1,17 \\
Inovação & 965 & 1,04 & 10,00 & 7,41 & 1,63 \\
Planejamento formal & 965 & 1,45 & 10,00 & 7,99 & 1,54 \\
Dedicação & 965 & 1,11 & 10,00 & 6,85 & 1,65 \\
Relacionamento & 965 & 3,73 & 10,00 & 8,38 & 1,35 \\
Pensamento Analítico & 965 & 3,28 & 10,00 & 8,43 & 1,20 \\
Desafio & 965 & 1,65 & 10,00 & 7,93 & 1,72 \\
\hline
\end{tabular}

Fonte: Dados da pesquisa - 2006.

Observa-se, na Tabela 4, que os construtos risco, competência estratégica, pensamento analítico, empatia, planejamento formal, desafio e inovação demonstram as maiores médias. Isso significa que os empreendedores tendem a ter a maior prevalência desses traços, o que pode indicar 0 perfil básico dos empresários. A baixa média do construto dedicação pode indicar que, ao menos para esses empresários, abrir mão da família e dos seus demais objetivos não é um fato muito comum, isto é, tais empresários têm outras atividades e interesses que vão além do sucesso daquele negócio. Esses dados indicam que a busca de equilíbrio entre trabalho e família, profissão e lazer é relativamente comum entre eles. Além disso, buscou-se identificar quais fatores são determinantes do perfil empreendedor, bem como de suas dimensões particulares. Para essa ação, recorreu-se, no caso apresentado em seqüência, à correlação não paramétrica de spearman, devido a sua maior robustez, em casos extremos nas variáveis analisadas, e porque algumas variáveis são claramente ordinais, tais como o faturamento bruto das empresas (PESTANA e GAGEIRO, 2003). Com base nessa perspectiva, fez-se a avaliação da relação entre os fatores e as variáveis das empresas estudadas e analisadas. 


\subsection{AVALIAÇÃO DA RELAÇÃO ENTRE O PPE E O DESEMPENHO DO NEGÓCIO}

Para avaliar o modelo de pesquisa, utilizou-se a Modelagem de Equações Estruturais, pois a técnica tem a capacidade de lidar com erros de mensuração e relações entre construtos em uma única análise. Para testar o modelo global, obteve-se uma amostra agregada de 965 casos para um total de 97 parâmetros livres, o que indica um total de 9,94 observações na amostra para cada parâmetro estimado no modelo. 0 modelo testado na pesquisa, utilizando somente as estruturas fatoriais, é representado pela figura 3.

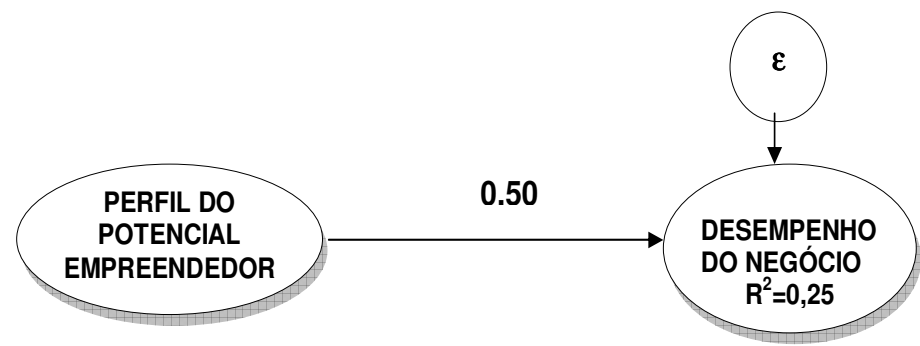

\section{Figura 3: Resultados da avaliação do impacto do PPE sobre desempenho}

Obs: A carga padronizada é significativa ao nível de 0,01\%.

Fonte: Dados da pesquisa - 2006.

O ajuste do modelo pode ser verificado na Tabela 5.

Tabela 5 - Ajustes do modelo

\begin{tabular}{c|c|c|c}
\hline ÍNDICE & VALOR & ÍNDICE & VALOR \\
\hline$\square^{2}$ & 3135,24 & IFI & 0,83 \\
g.l & 893 & TLI & 0,82 \\
Sig. & 0,00 & CFI & 0,83 \\
$\square 2 / g . I$ & 3,51 & RMSEA & 0,05 \\
GFI & 0,87 & RMSEALO & 0,05 \\
AGFI & 0,85 & RMSEAHI & 0,05 \\
PGFI & 0,78 & PCLOSE & 0,19 \\
NFI & 0,78 & HFIVE & 297 \\
RFI & 0,77 & HONE & 306 \\
\hline
\end{tabular}

Fonte: Dados da pesquisa - 2006

Considerando as variáveis que compõem a PPE, pode-se dizer que esse construto tem um impacto razoável sobre o desempenho das empresas, conforme relatado pelos gestores. Como se verifica na pesquisa, o construto PPE foi capaz de explicar aproximadamente $25 \%$ da variância do desempenho das empresas e do negócio. Assim, 0 modelo obteve resultados satisfatórios, conseguindo atingir patamares moderados de ajuste nos índices explicados anteriormente $e$ apresentados na figura 3. 


\section{CONSIDERAÇÕES FINAIS}

De modo a cotejar os resultados desta pesquisa sobre o tema empreendedorismo, com trabalhos e estudos anteriores, elaborou-se um comparativo entre os fatores identificados no PPE com os fatores definidos pelos autores referendados, dispostos na Tabela 6.

\begin{tabular}{|c|c|c|c|c|c|c|c|c|c|}
\hline PPE & $\begin{array}{c}\text { MCCLELLAND } \\
1961 \\
\text { CCE'S }\end{array}$ & $\begin{array}{c}\text { SCHUMPETER } \\
1982\end{array}$ & $\begin{array}{c}\text { CARLAND } \\
1996 \\
\text { CEI }\end{array}$ & $\begin{array}{c}\text { TIMMONS } \\
1998\end{array}$ & $\begin{array}{c}\text { FILION } \\
1999\end{array}$ & $\begin{array}{l}\text { MINTZBERG } \\
2001\end{array}$ & $\begin{array}{c}\text { DORNELAS } \\
2001\end{array}$ & $\begin{array}{l}\text { DRUCKER } \\
1992 / 2003\end{array}$ & $\begin{array}{c}\text { BYGRAVE } \\
2003 \\
\text { GEM }\end{array}$ \\
\hline $\begin{array}{c}\text { Competência } \\
\text { Estratégica }\end{array}$ & & & Postura Estratégica & & & Estratégia & & & Estratégia \\
\hline Risco & $\begin{array}{l}\text { Correr risco } \\
\text { calculado }\end{array}$ & Risco & Propensão ao Risco & Incerteza & & Incerteza & Risco & Risco & Assumir Riscos \\
\hline $\begin{array}{l}\text { Planejamento } \\
\text { Formal }\end{array}$ & Planejamento & Lucratividade & & Plano de Negócios & Visão & & $\begin{array}{l}\text { Plano de } \\
\text { Negócios }\end{array}$ & & \\
\hline Dedicação & Persistência & & & & Persistência & & & & Valores Pessoais \\
\hline Relacionamento & $\begin{array}{l}\text { Comprometi- } \\
\text { mento }\end{array}$ & & & Carisma & & & & & Relacionamento \\
\hline
\end{tabular}

\section{Quadro 1 - Comparação entre os fatores do PPE com os autores pesquisados}

Fonte: Elaborado pelos autores 
Refinamentos nas escalas e em pesquisas subseqüentes são recomendadas para dar maior sustentação à continuidade dos estudos. Por outro lado, alguns pontos e considerações sugeridos por este estudo podem ser significativos na melhoria da gestão de empreendimentos, uma vez que os empreendedores, com a utilização da escala PPE, podem avaliar seus perfis, habilidades e deficiências e aprimorar os fatores que demonstram maior impacto na natureza do empreendimento.

Percebe-se, também, que estudos são realizados com 0 intuito de se identificar os aspectos relacionados aos resultados e ao desempenho das empresas no contexto gerencial, mas poucos, ou quase nenhum, encontram-se estruturados em bases que associam 0 potencial do perfil empreendedor com o desempenho do negócio, buscando explicar o quanto esta integração impacta no sucesso e nos resultados dos negócios.

Neste estudo foi utilizado como referência o significado atribuído, pelo dicionário Houaiss (2003), à palavra perfil, que significa a descrição de uma pessoa em traços que ressaltam sua característica básica, informação concisa e informal sobre a vida que engloba caráter, gênio, índole e temperamento. $\mathrm{O}$ significado de potencial contempla quem ainda não desenvolveu plenamente suas tendências inatas ou intrínsecas, quem ainda não atingiu a plenitude da sua forma, um conjunto de qualidades latentes de um indivíduo, potencialidade, aptidão, capacidade, competência, inteligência e talento.

Este estudo pretende colaborar para o desenvolvimento do tema empreendedorismo e para a construção de um índice que identifique o perfil do potencial empreendedor brasileiro. Também tem 0 intuito de indicar seu impacto no desempenho de um pequeno negócio, e possibilitar que possa ser aplicado em outros grupos, com o objetivo de dar continuidade a essa linha de pesquisa, conforme proposto na figura 4.

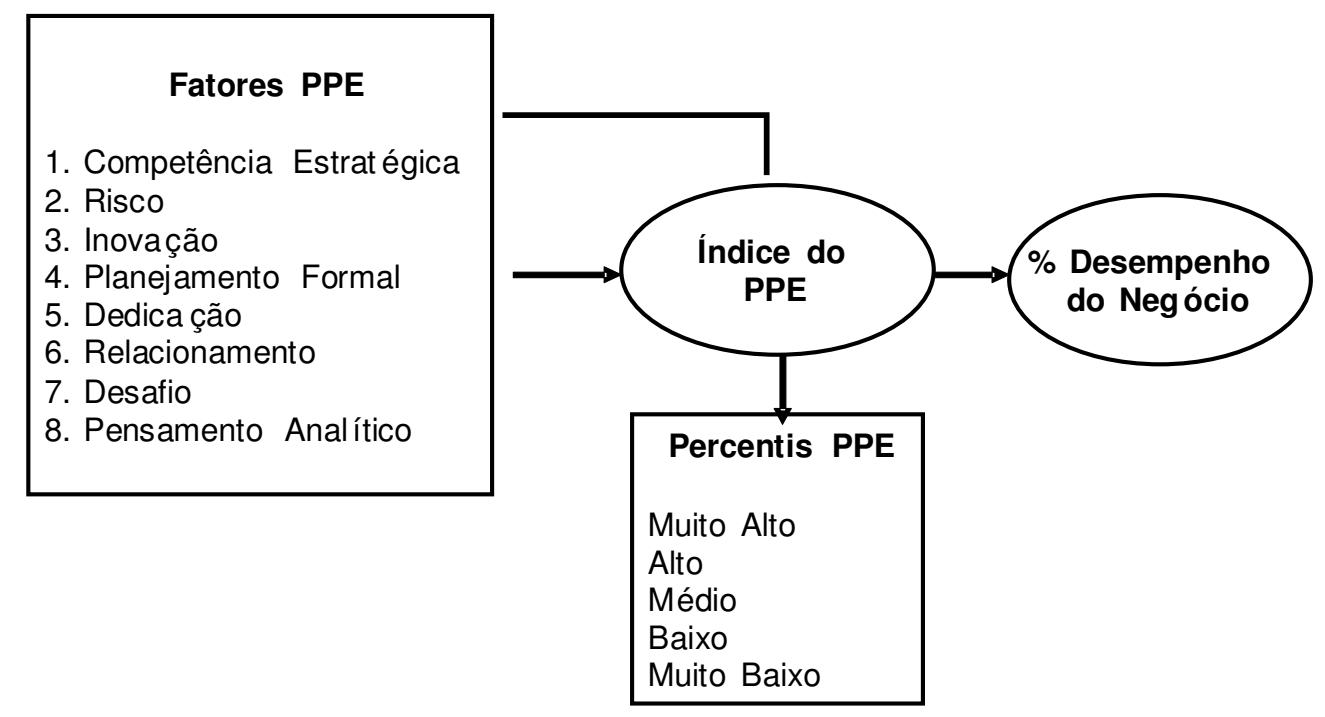

\section{Figura 4: Proposição de modelo do perfil do potencial empreendedor e impacto no desempenho do negócio}

Fonte: os autores.

De forma exploratória, utilizando-se das sugestões de Kline (1998), de empregar valores ponderados pelos pesos estruturais não ponderados, para calcular médias dos fatores (MFi), a cada um dos construtos, buscou-se calcular um índice total do Perfil do Potencial Empreendedor - PPE. A proposta de Kline (1998) utiliza a seguinte fórmula, que foi aplicada: 


$$
M F_{i}=\frac{\sum_{I=1}^{K} W_{K} X_{K I}}{\sum_{I=1}^{K} W_{K}}
$$

Em que: $W_{K}$ é o peso de regressão do k-ésimo indicador obtido na AFC.

$X_{K I}$ é o valor observado do k-ésimo indicador para o i-ésimo respondente.

Deste modo, procedeu-se o cálculo de um índice único PPE para cada empreendedor da amostra. Em seguida, analisaram-se os quintis do PPE (valores do índice estrutural de PPE) observados. Esse procedimento pode contribuir para classificar os empreendedores em grupos com afinidades relacionadas ao perfil do potencial empreendedor, bem como conscientizá-los do nível do seu PPE individual. Os quintis obtidos se encontram descritos na Tabela 7.

Tabela 7 - Percentis do PPE na população

\begin{tabular}{l|r}
\hline \multicolumn{1}{c|}{ CARACTERIZAÇÃO SUGERIDA PELOS AUTORES } & \multicolumn{1}{c}{ ÍNDICE PPE } \\
\hline Muito alto & $\geq 8,87$ \\
\hline Alto & $8,43 \leq 8,87$ \\
\hline Médio & $8,02 \leq 8,43$ \\
\hline Baixo & $7,46 \leq 8,02$ \\
\hline Muito baixo & $\leq 7,46$ \\
\hline
\end{tabular}

Fonte: dados da pesquisa - 2006.

Essa análise, exposta na Tabela 7, sugere a possibilidade de, além de mensurar o perfil do empreendedor, verificar em qual percentil um dado empreendedor se encontra dentro da população, permitindo a comparação com demais empreendedores. Esse procedimento pode também ser realizado associando-se os níveis de PPE com o desempenho da empresa.

Sugere-se, dessa maneira, realizar outras pesquisas complementares a este estudo, que possam explicar os $75 \%$ da variância não relacionada ao PPE. Indica-se, também, que aspectos antecedentes e contributivos do desempenho do negócio podem ser acrescentados a outras pesquisas, de modo a avançar nesse campo.

\section{REFERÊNCIAS}

BYGRAVE, D.W.; ZACHARAKIS, A. The Portable MBA in Entrepreneurship. 3.ed. New Jersey: Wiley, 2004. 494p.

CARLAND, J.A.; CARLAND, J.W. The Theoritetical Bases and Dimensionality of the Carland Entrepreneurship Index. Proceedings of the RISE 96 Conference, University of Jyvaskylâ, Finlândia, 1996. p.1-24.

CARLAND, J.A.; CARLAND, J.W.; ENSLEY, M.D. The Search for the Lead Entrepreneur: Identification Through the Measurement of Entrepreneurial Drive and Skills. Babson College All Rights Reserved. Last Updated January, 1999. 
CARLAND,J; CARLAND.J.A; HOY,F. An Entrepreneruship Index: an empirical validation. In Frontiers do Entrepreneurship Research, 1992, França. Proccedings...Massachussets: Babson College, 1992.

DORNELAS, J.C.A. Empreendedorismo: transformando idéias em negócios. Rio de Janeiro: Campus, 2001.

DOLABELA, F. O Segredo de Luísa. São Paulo: Cultura e Editores Associados, 1999.

DRUKER, P.F. Administrando para o futuro: os anos 90 e a virada do século. São Paulo: Pioneira, 1992.

DRUCKER, P.F. Inovação e espírito empreendedor: prática e princípios. São Paulo: Pioneira, 2003. 378p.

FILION, L.J. Empreendedorismo: empreendedores e proprietários-gerentes de pequenos negócios. Revista de Administração, São Paulo, v.34, n.2, p.5-28, 1999.

GEM - Global Entrepernurship Monitor. 2003. Executive Report. Maria Minniti; William D. Bygrave; Erkko Autio. Babson College, US and London Business School, UK .Boston:2003, 42p.

GEM - Global Entrepernurship Monitor. 2004. Executive Report. Zoltam J.Acs; Pia Arenius; Michael Hay Maria Minniti; William D. Bygrave; Erkko Autio. Babson College, US and London Business School, UK .Boston: 2004, 48p.

GEM - Global Entrepernurship Monitor. 2005. Executive Report. Maria Minnuti; William D. Bygrave; Erkko Autio. Babson College, US and London Business School, UK. Boston: 2006, 48p.

GIL, A.C. Como elaborar projetos de pesquisa. São Paulo: Atlas, 1991.

GOODE, W.J.; HATT, P.K. Métodos em pesquisa social. 3.ed. São Paulo: Cia Editora Nacional, 1969.

HAIR Jr. Joseph F. et al. Multivariate data Analysis. 5th ed. Upper Saddle River (NJ): Prentice Hall, 1998.

HARVARD BUSINESS REVIEW. Entrepreneurship. Boston: Harvard Business School Press, 1999.

HOUAISS, A. Dicionário Houaiss de sinônimos e antônimos. Rio de Janeiro: Objetiva, 2003. 953p.

INÁCIO Jr., E. Empreendedorismo e liderança criativa: um estudo com os proprietários-gerentes de empresas incubadas no estado do Paraná. 2002. Dissertação (Mestrado em Administração) Universidade Federal de Maringá, Maringá, 2002.

KLINE, R. B. Principles and practice of structural equation modeling. New York: The Guilford Press, 1998.

KORNIJEZUK, Fernando .B.S. Características empreendedoras de pequenos empresários de Brasília. 2004. 128f. Dissertação (Mestrado em Administração) - Faculdade de Economia, Administração, Contabilidade e Ciência da Informação e Documentação, Universidade de Brasília, Brasília, 2004.

LONGENECKER, J.G.; MOORE, C.W.; PETTY, J.W. Administração de pequenas empresas. São Paulo: Makron Books, 1997.

MCCLELLAND, D. The achieving society. New York: VanNostrand, 1961. 
MINTZBERG, H.; QUINN, J. B. O processo da estratégia. Porto Alegre: Bookman, 2001.

NETEMEYER, R. G.; BEARDEN, W. O.; SHARMA, S. Scaling procedures: Issues and Applications. SAGE, 2003.

PESTANA, M. H.; GAGEIRO, J. N. Análise de dados para Ciências Sociais - complementaridade do SPSS. 2. ed. Lisboa, 2000.

SCHUMPETER, J.A. Teoria do desenvolvimento econômico. São Paulo: Abril Cultural, 1982 [1934].

SEBRAE. Fatores condicionantes e taxa de mortalidade de empresas no Brasil. Relatório de pesquisa - Brasília, 2004.

SEBRAE - GEM - Pesquisa Global Entrepreneurship Monitor - Empreendedorismo no Brasil - Relatório Global. Brasília: 2001, 2002, 2003, 2004,2005 e 2006.

SEBRAE - Boletim Estatístico de Micro e Pequenas Empresas - Observatório Sebrae - Brasília: 1ำ semestre, 2005.

TABACHINIK, B. G.; FIDELL, L. S. Using Multivariate Statistics. 4 ed. New York: HarperCollins, 2001.

THIMMONS, Jeffry A. The Entrepreneurial Mind. Andover, Massachussetts: Brick House Publishing Company,1989. 187p.

\section{ENTREPRENEURIAL POTENTIAL PROFILE MEASUREMENT AND IT'S IMPACT ON SMALL BUSINESS PERFORMANCE}

The entrepreneurship issue has been widely broadcasted among both academic and business environment by means of publications, practical cases and examples from entrepreneurs who are well succeeded in their business career. Several articles, seminars and conferences have addressed the issue and also have inspired researchers and scholars to identify which characteristics compose the entrepreneur's profile. Small companies are considered to be one of the main agents of development and economic growth of a country as they contribute in two different ways: they create more job opportunities and technological innovations. In Brazil, for example, small companies represent $98 \%$ of the total running companies and $59 \%$ of the total workforce. Hence, small companies have a central importance for the social system in a capitalist society. Considering this scenario, the present research aims to build an instrument to identify which are the main factors that compose the entrepreneur's profile. In order to achieve that objective, 965 questionnaires were collected. According to the results of the research, the EPP- Entrepreneur Potential Profile is composed by eight factors: strategic competence, risk, innovation, formal planning, relationship, analytical thinking, dedication and challenge. Through Structural Equation Modeling, it was verified that EPP (Entrepreneur Potential Profile) could explain $25 \%$ of performance of a small business. This study contributes with the development of a scale to measure Entrepreneur Potential Profile, with the proposal of a Entrepreneur Potential Profile Index - EPPI (using structural weights), associated with a typology of EPPI levels (low to high Entrepreneur Potential), that can help entrepreneurs to understand their profile and compare it with the population. Also, this work suggests that Entrepreneurship Profile Potential is an antecedent of business performance, and should be considered in new studies that aim to improve performance of small business firms.

Key words: Search Terms. Entrepreneurship. Small business. Performance.

Data de Submissão: dezembro de 2006 Data de Aceite: março de 2007 